\title{
Nebulised pentamidine as treatment for Pneumocystis carinii pneumonia in the acquired immunodeficiency syndrome
}

\author{
ROBERT F MILLER, PETER GODFREY-FAUSSETT, STEPHEN J G SEMPLE
}

From the Department of Medicine, University College and Middlesex School of Medicine, Middlesex Hospital, London

ABSTRACT Nebulised pentamidine was used to treat 30 patients with Pneumocystis carinii pneumonia. Fourteen patients (group 1) received pentamidine isethionate $4 \mathrm{mg} / \mathrm{kg}$ (six patients) or 8 $\mathrm{mg} / \mathrm{kg}$ (eight patients) via a standard jet nebuliser (Acorn, system 22) with a flow rate of $81 / \mathrm{min}$. The aerosol droplets had a mass median aerodynamic diameter of $2.6 \mu \mathrm{m}$ (geometric standard deviation (GSD) 2.9) and $46 \%$ of droplets were less than $3.9 \mu \mathrm{m}$. A further 16 patients (group 2) received $8 \mathrm{mg} /$ $\mathrm{kg}$ pentamidine via a jet nebuliser with baffles to limit droplet size to below $4 \mu \mathrm{m}$ (Respirgard II). This generated aerosol droplets with a mass median aerodynamic diameter of $0.8 \mu \mathrm{m}$ (GSD 1.5$)$ and $98 \%$ were less than $3.9 \mu \mathrm{m}$. Only three of the 14 patients in group 1 responded clinically to treatment, one after the lower dose of pentamidine. Treatment was discontinued in 10 patients and one patient died at bronchoscopy from haemorrhage. Thirteen of the 16 patients in group 2 responded. Side effects occurred infrequently; two patients from group 1 had a cough, six patients (four from group 2) had contact bleeding at bronchoscopy, and two further patients had haemoptysis. The differing response rate may be due to differences in the mean droplet size of the aerosols produced by the nebulisers. Nebulised pentamidine $(8 \mathrm{mg} / \mathrm{kg}$ ) when delivered by Respirgard II nebuliser appears to be as effective as conventional treatment for Pneumocystis carinii pneumonia of mild to moderate severity.

\section{Introduction}

Pneumocystis carinii pneumonia is the most common lethal opportunist infection in patients with the acquired immunodeficiency syndrome (AIDS). ${ }^{1}$ Current first line treatment is with high dose trimethoprim-sulphamethoxazole (co-trimoxazole) given intravenously or orally. Side effects occur frequently and necessitate a change in treatment in up to half the patients. ${ }^{2}$ Alternative treatment with pentamidine isethionate given intramuscularly or intravenously is also associated with a high incidence of side effects. ${ }^{3}$ With either treatment up to $86 \%$ of patients with pneumocystis pneumonia will respond ${ }^{3}$ with an improvement in arterial oxygen tension $\left(\mathrm{PaO}_{2}\right)$, clearing of the chest radiograph, defervescence of fever, and a reduction in cough and dyspnoea.

Address for reprint requests: Dr R F Miller, Department of Medicine, University College and Middlesex School of Medicine, Middlesex Hospital, London W1N 8AA.

Accepted 13 April 1989
Nebulised pentamidine is known to be effective against pneumocystosis in rats. ${ }^{4}$ Both in the rat and in man nebulised delivery of the drug to the lung produces high concentrations of pentamidine in bronchoalveolar lavage specimens with little pulmonary clearance for at least 24 hours. $^{5}$

Nebulised pentamidine was studied in an open prospective trial as sole treatment for pneumocystis pneumonia in patients with AIDS.

\section{Methods}

From June 1987 to June 1988 patients with antibodies to human immunodeficiency virus 1 (HIV-1) presenting with pneumocystis pneumonia were considered for treatment with nebulised pentamidine. Patients were excluded if their $\mathrm{PaO}_{2}$ while they were breathing room air was less than $5.9 \mathrm{kPa}$ or if treatment with intravenous pentamidine or co-trimoxazole had already been started. Treatment consisted of inhalation of nebulised pentamidine once daily for 21 days supervised by one of the investigators or by nursing staff. 


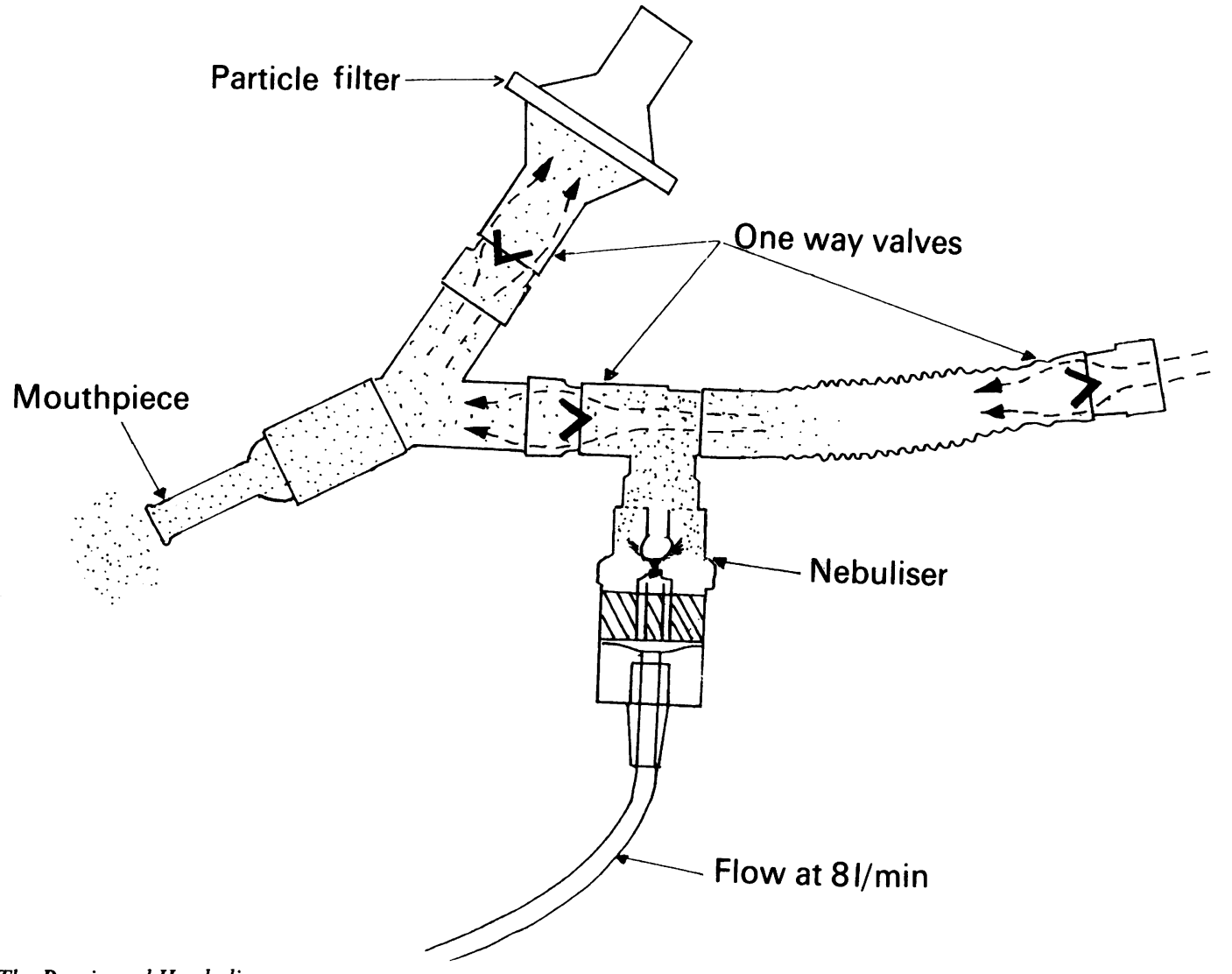

The Respirgard II nebuliser.

The dose of pentamidine isethionate (May and Baker) used was $4 \mathrm{mg} / \mathrm{kg}$ body weight for the first six patients and $8 \mathrm{mg} / \mathrm{kg}$ for the remainder. The pentamidine was dissolved in $8 \mathrm{ml}$ sterile water.

Initially we used an Acorn nebuliser (system 22, Medic Aid) and later a Respirgard II nebuliser (Marquest, Colorado).* This is a jet nebuliser with baffles, which act as one way valves that prevent the passage of large $(>4 \mu \mathrm{m})$ droplets and also direct exhalation to a filter to prevent environmental contamination (figure). The nebulisers were driven with compressed air at $8 \mathrm{l} / \mathrm{min}$; each nebulisation took 15-30 minutes.

Before treatment patients were examined and their temperatures recorded, a chest radiograph was obtained, and arterial blood gas tensions determined while they were breathing room air. During the treatment period clinical examinations were made daily and temperature recorded. Chest radiographs were obtained and $\mathrm{PaO}_{2}$ recorded at weekly intervals, or more frequently if indicated. Failure to respond to treatment was defined as $(a)$ worsening of clinical symptoms; $(b)$ persistence or worsening of fever; (c) deterioration of chest radiograph appearances; (d) deteriorating $\mathrm{PaO}_{2}$. Patients who did not respond $\widetilde{x}$ had their treatment changed to intravenous high dose co-trimoxazole unless they were known to be hypersensitive to this drug, in which case intravenous $\subseteq$ pentamidine treatment was started. While they were having this treatment blood glucose concentrations윽 were estimated twice daily. All patients had normal $>$ renal function, clotting times, and platelet counts.

A Malvern $2600 \mathrm{C}$ laser analyser (Malvern N Instruments) was used to measure the droplet size distributions of the pentamidine aerosols generated by the two nebuliser systems. The distribution of aerosol $w$ droplet size is described by its mass median aerodynamic diameter (MMAD) in $\mu \mathrm{m}$ (half the mass of theo aerosol consists of droplets with a diameter less than the MMAD) and the geometric standard deviation? (GSD), a measure of the heterogeneity of the droplet $\frac{7}{7}$ sizes. The percentage of droplets below $3.9 \mu \mathrm{m}$ was also calculated.

*UK distributor JMS Supplies Ltd, 4 Oakham Drive Parkwood Industrial Estate, Sheffield SE3 9QX. 
Results

\section{NEBULISER}

The aerosol characteristics with the nebulisers running as described were: Acorn-MMAD 2.6 $\mu \mathrm{m}$, GSD 2.9; $46.5 \%$ of droplets $<3.9 \mu \mathrm{m}$. Respirgard II-MMAD $0.8 \mu \mathrm{m}$, GSD $1.5 ; 98 \cdot 1 \%$ of droplets $<3.9 \mu \mathrm{m}$.

\section{PATIENTS}

Thirty patients were treated. All were male homosexuals and HIV-1 antibody positive and none had abused intravenous drugs. Their ranges ranged from 21 to 56 (mean $39 \cdot 7$ ) years.

The first 14 patients received pentamidine via the Acorn nebuliser (group 1). Pneumocystis pneumonia was confirmed at bronchoscopy in 12 patients and from induced sputum in one. One patient with clinical features, radiographic abnormalities and arterial hypoxaemia typical of pneumocystis pneumonia declined the induced sputum test and bronchoscopy and was given nebulised pentamidine empirically. Three patients responded rapidly to treatment, including the patient treated empirically; one responder had received $4 \mathrm{mg} / \mathrm{kg}$ pentamidine. One patient died from massive haemorrhage after a transbronchial biopsy. In the remaining 10 patients treatment was considered to be unsuccessful after 2-15 days on the basis of one or more of the following: continuing fever (8), clinical deterioration (5), increasing arterial hypoxaemia (6), deteriorating radiographic appearances (3). Treatment was changed in these patients to intravenous cotrimoxazole in nine and to intravenous pentamidine and methylprednisolone in one patient known to be hypersensitive to co-trimoxazole. Nine of the 10 patients recovered (table). The remaining 16 patients

\section{Treatment and outcome in the 10 patients whose initial} treatment with nebulised pentamidine via the Acorn nebuliser was unsuccessful and was changed, mainly to intravenous cotrimoxazole

\begin{tabular}{|c|c|}
\hline $\begin{array}{l}\text { Patient } \\
\text { No }\end{array}$ & Outcome \\
\hline $\begin{array}{l}1 \\
2 \\
3 \\
4\end{array}$ & $\begin{array}{l}\text { Deteriorated, intravenous pentamidine added } \rightarrow \text { died } \\
\text { Recovered } \\
\text { Recovered } \\
\text { Deteriorated with intravenous pentamidine, } \\
\text { methylprednisolone added } \rightarrow \text { recovered }\end{array}$ \\
\hline 5 & Recovered \\
\hline $\begin{array}{l}6 \\
7\end{array}$ & $\begin{array}{l}\text { Recovered } \\
\text { Deteriorated, methylprednisolone added } \rightarrow \text { recovered }\end{array}$ \\
\hline 8 & $\begin{array}{l}\text { Rash/vomiting with intravenous co-trimoxazole, } \\
\text { changed to intravenous pentamidine and developed } 2 \\
\text { degree A-V block (Wenckebach). Changed to } \\
\text { trimetrexate } \rightarrow \text { recovered }\end{array}$ \\
\hline 9 & $\begin{array}{l}\text { Nausea and vomiting with intravenous co-trimoxazole, } \\
\text { changed to intravenous pentamidine } \rightarrow \text { recovered }\end{array}$ \\
\hline 10 & $\begin{array}{l}\text { Deteriorated, methylprednisolone and intravenous } \\
\text { pentamidine added } \rightarrow \text { recovered }\end{array}$ \\
\hline
\end{tabular}

*Hypersensitive to co-trimoxazole. (group 2) received pentamidine via the Respirgard II nebuliser. Pneumocystis pneumonia was confirmed in 15 ; one patient with a typical presentation but negative results from bronchoscopy was treated empirically. Thirteen patients responded, including the one treated empirically. One developed worsening dyspnoea and fever after receiving nebulised pentamidine for 19 days and another remained febrile and became hypoxaemic (fall in $\mathrm{PaO}_{2}$ from 12.7 to $5.5 \mathrm{kPa}$ after six days); both responded rapidly to intravenous co-trimoxazole. A third patient deteriorated after eight days of nebulised pentamidine, becoming hypoxaemic $\left(\mathrm{PaO}_{2} 5.8 \mathrm{kPa}\right)$; he continued to deteriorate after treatment was changed to intravenous co-trimoxazole, but recovered rapidly when methylprednisolone was added.

Two patients in group 1 had to discontinue treatment because of severe coughing during nebulisation, despite the administration of nebulised salbutamol before the nebulised pentamidine. No patient had clinical or biochemical evidence of hypoglycaemia. Two patients in group 1 and four in group 2 had substantial contact bleeding and oozing at bronchoscopy, though the quantities of blood produced were small and none had haemoptysis during or after the bronchoscopy. Two further patients, one from each group, had contact bleeding and haemoptysis, $10 \mathrm{ml}$ in one case and $35 \mathrm{ml}$ in the other.

No patient in either group had an early relapse (less than four weeks) after treatment. The three responders in group 1 have been followed up for 14,17 , and 20 months and have had no recurrence of pneumocystis pneumonia. One patient in group 2 died from a cerebral lymphoma four weeks after completing nebulised pentamidine treatment and another died after four months with extensive cutaneous and endobronchial Kaposi's sarcoma and infection with Mycobacterium avium-intracellulare and Haemophilus influenzae, which were in sputum and blood cultures. A third patient died after six months from a cause unrelated to AIDS. The remaining 10 patients have been followed up for eight to 12 months (median 10 months) and have had no recurrence of pneumocystis pneumonia. The prophylactic regimens these patients have used are daily oral co-trimoxazole and zidovudine (11 patients) or nebulised pentamidine, $150 \mathrm{mg}$ once a fortnight via the Respirgard nebuliser (3 patients, one of whom has also been taking daily zidovudine).

\section{Discussion}

Up to $70 \%$ of patients receiving high dose cotrimoxazole for pneumocystis pneumonia will develop side effects within seven to 10 days of beginning treatment and a change of treatment will be necessary in over half of these. ${ }^{2}$ The side effects include nausea 
and vomiting, rashes (including erythema multiforme and Stevens-Johnson syndrome), leucopenia in over half the patients, and abnormal liver function in over a third. $^{3}$ Other side effects include megaloblastic anaemia, thrombocytopenia, and renal failure. For alternative treatment intravenous pentamidine is used; this also has important side effects-nephrotoxicity (causing a rise in serum creatinine and blood urea concentrations) in up to $64 \%$, hypotension in $27 \%$, and hypoglycaemia in $21 \% .^{3}$ Other reported side effects include nausea and vomiting, rashes, peripheral neuropathy, hepatotoxicity, cardiac arrhythmias, marrow suppression, pancreatitis, hyperkalaemia, and hypocalcaemia.

In view of the many side effects when treatment is administered parenterally and because Pneumocystis carinii infection affects the alveoli of the lung exclusively there are cogent reasons for delivering treatment of proved efficacy locally. Nebulisation of pentamidine produces higher drug concentrations in bronchoalveolar lavage fluid than the intravenous route of administration ${ }^{5}$ and little, if any, nebulised drug is absorbed systemically. Montgomery et al treated 15 patients during their first episode of pneumocystis pneumonia with nebulised pentamidine in an open study using the Respirgard nebuliser. Thirteen patients responded. ${ }^{6}$ The only side effect noted was cough in 12 patients. We undertook this open prospective study to define the clinical indications for using nebulised pentamidine as treatment for pneumocystis pneumonia and also to confirm the results of Montgomery et al.

We initially chose the Acorn nebuliser system because it was widely available and robust, and was already in use for nebulising bronchodilators and antibiotics. The size distribution of droplets produced by this system had previously been studied ${ }^{7}$ and our own measurements confirm the earlier data. Later we used the Respirgard II and again confirmed the data on droplet size. ${ }^{5}$ There were striking differences in the rate of response to nebulised pentamidine given by the two systems. This may be due to the differences in droplet size generated by the systems. It has been shown that the optimum size for a beta adrenergic bronchodilator aerosol is less than $5 \mu \mathrm{m}$. $^{8}$

Droplets larger than $10 \mu \mathrm{m}$ will not penetrate the tracheobronchial tree and will become impacted in the nose, mouth, larynx, and trachea. Droplets of less than $1 \mu \mathrm{m}$ will penetrate to the periphery of the lung, but tend to be expired without deposition. With the Acorn system there is a wide scatter of droplet size, $53.5 \%$ of droplets being $4 \mu \mathrm{m}$ or more, so deposition within the upper airways would have reduced the dose delivered to the alveoli. The Respirgard II also contains a $70 \mathrm{ml}$ reservoir between the mouthpiece and the point of nebulisation, which might increase the proportion of appropriately sized aerosol droplets delivered to the $\stackrel{0}{x}$ peripheral airways. After treatment failed in five of the $\overrightarrow{\vec{D}}$ first six patients we realised that about half of the drug $\frac{?}{0}$ remained trapped in the nebuliser circuit after nebul- $\frac{C}{5}$ isation. The dose of pentamidine was then doubled to $\frac{\bar{O}}{\bar{D}}$ $8 \mathrm{mg} / \mathrm{kg}$ body weight. On the assumption that half the $\vec{\nabla}$ dose was left in the nebuliser, this gave an effective dose of $4 \mathrm{mg} / \mathrm{kg}$. Montgomery et al also found that $\tilde{c}^{2}$ about half the dose of pentamidine remained in the $\overrightarrow{0}$ nebuliser at the end of nebulisation with the Respirgard II system, ${ }^{6}$ so we persisted with the higher dose $\vec{\omega}$ with Respirgard II.

It has been suggested that there is a subgroup of $\vec{x}$ patients with pneumocystis pneumonia who have a poor prognosis regardless of what treatment is used; $i v$ $90 \%$ of patients with pneumocystis pneumonia who of fail to respond to high dose co-trimoxazole will also $O$ fail to respond to intravenous pentamidine. ${ }^{9}$ Our initial poor response rate is unlikely to be due to $\overrightarrow{\vec{c}}$ inadvertent selection of such patients since nine of the 10 non-responders in group 1 and all three non- $\vec{\theta}$ responders in group 2 subsequently responded to conventional treatment.

We initially excluded patients whose $\mathrm{PaO}_{2}$ was under $5.9 \mathrm{kPa}$ when they were breathing room air. After observing treatment failure in five of the first six patients, three of whom had a fall in $\mathrm{PaO}_{2}$, we ֶ subsequently modified our exclusion criteria to $\stackrel{\mathbb{Q}}{\complement}$ exclude patients whose $\mathrm{PaO}_{2}$ was under $7 \cdot 2 \mathrm{kPa}$.

Cough was a problem in two patients in group $1, \frac{\text { 을 }}{3}$ necessitating discontinuation of treatment. This may have been due to the higher proportion (over half) of aerosol droplets that were large and therefore deposited in the upper airways. Other groups have 음 also reported cough and bronchoconstriction. ${ }^{10} \underset{\otimes}{\check{D}}$ Pentamidine isethionate solution when dissolved in $\dot{\sigma}$ water at a concentration of $60-100 \mathrm{mg} / \mathrm{ml}$ (similar to the concentration nebulised) has a $\mathrm{pH}$ of 5.4 and is hypotonic (osmolality $160 \mathrm{mmol} / \mathrm{kg}$ at $100 \mathrm{mg} / \mathrm{ml}^{11}$ ). These physicochemical properties may explain the $ᄋ$ cough and bronchoconstriction and perhaps also the contact bleeding and oozing. None of our patients had clinical or biochemical evidence of hypoglycaemia as reported by other workers. ${ }^{12}$

Treatment with nebulised pentamidine at a dose of $8 \mathrm{~N}$ $\mathrm{mg} / \mathrm{kg}$ given via a Respirgard II nebuliser appears to be as effective as conventional treatment for pneumo- 0 cystis pneumonia of mild to moderate severity, with $\mathrm{a}_{\odot}^{-}$

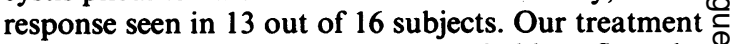
failures with the Acorn system probably reflect the higher proportion of droplets of $4 \mu \mathrm{m}$ or more, which ${ }_{0}$ never reach the alveoli, a limitation that was possibly ${ }^{\circ}$ compounded in six patients by the use of a lower dose $\mathbb{D}$ of pentamidine.

We would like to thank Professor M Newton and Dr 
$\mathrm{K}$ Taylor of the School of Pharmacy, University of London, for allowing us to use the Malvern $2600 \mathrm{C}$ laser analyser, and Miss Annette Skinner for typing the manuscript.

\section{References}

1 Centres for Disease Control. CDC update. Acquired immunodeficiency syndrome-United States. $M M W R$ 1986;35:17-21.

2 Wharton M, Coleman DL, Fitz G, et al. Trimethoprimsulfamethoxazole or pentamidine for Pneumocystis carinii pneumonia in the acquired immunodeficiency syndrome. Ann Interm Med 1986;105:37-44.

3 Sattler FR, Cowan R, Neilsen DM, Ruskin J. Trimethoprim-sulfamethoxazole compared with pentamidine for treatment of Pneumocystis carinii pneumonia in the acquired immunodeficiency syndrome. Ann Intern Med 1988;109:280-7.

4 Debs RJ, Blumenfeld EN, Brunette EN, et al. Successful treatment with aerosolised pentamidine of Pneumocystis carinii pneumonia in rats. Antimicrob Agents Chemother 1987;31:37-41.
5 Montgomery AB, Debs RJ, Luce JM, et al. Selective delivery of pentamidine to the lung by aerosol. Am Rev Respir Dis 1988;137:477-8.

6 Montgomery A, Debs R, et al. Aerosolised pentamidine as sole therapy for pneumocystis pneumonia in patients with acquired immunodeficiency syndrome. Lancet 1987; ii:480-3.

7 Clay MM, Pavia D, Newman SP, Clarke SW. Factors influencing the size distribution of aerosols from jet nebulisers. Thorax 1983;38:755-9.

8 Rees BJ, Clark TJH. The importance of particle size in response to inhaled bronchodilators. Eur J Respir Dis 1982;63(suppl 119):73-8.

9 Murray J, Felton C, Garay S, et al. Special report of a national heart, lung and blood institute workshop. Pulmonary complications of AIDS. $N$ Engl J Med 1984;310:1682-8.

10 Smith DC, Herd D, Gazzard BG. Reversible bronchoconstriction with nebulised pentamidine [letter]. Lancet 1988;ii:905.

11 McEvoy GK, ed. American Hospital Formulary Service. Drug information 87. Bethesda, Maryland: American Society of Hospital Pharmacists, 1987.

12 Karboski JA, Godley PJ. Inhaled pentamidine and hypoglycaemia. Ann Intern Med 1988;108:490. 